\title{
Cervical Cancer Epidemiology, Prevention and Screening among Women Living with HIV in the Americas region: A Systematic Review Protocol
}

\section{Epidemiología, prevención y detección temprana de cáncer de cuello uterino en mujeres con VIH en las Américas: protocolo de una revisión sistemática}

\author{
María Caicedo Martínez \\ Research Assistant, Hospital Universitario San Ignacio, \\ Centro Javeriano de Oncología, Bogotá, Colombia \\ Camila Ordóñez Reyes \\ Rural Physician, Hospital Universitario San Ignacio, \\ Bogotá, Colombia \\ Ginna Fernández Deaza \\ Research Assistant, Pontificia Universidad Javeriana, \\ Bogotá, Colombia \\ Bernardo Nuche Berenguer \\ Specialist HIV Key Population, Department of \\ Communicable Diseases and Environmental \\ Determinants of Health, Estados Unidos \\ Maeve Mello \\ Advisor, HIV/STI Prevention Department of \\ Communicable Diseases and Environmental \\ Determinants of Health, Estados Unidos \\ Raúl Murillo \\ Director of the Centro Javeriano de Oncología, \\ Hospital Universitario San Ignacio-Pontificia \\ Universidad Javeriana, Bogotá, Colombia
}

a Corresponding author: rmurillo@husi.org.co

How to cite: Caicedo Martínez M, Ordóñez Reyes C, Fernández Deaza G, Nuche Berenguer B, Mello M, Murillo R. Cervical cancer epidemiology, prevention and screening among women living with HIV in the Americas region: a systematic review protocol. Univ. Med. 2020;61(4). https://doi.org/10.11144/Javeriana. umed61-4.ccep

\section{ABSTRACT}

Background: Women living with HIV (WLHIV) are more prone to persistent infection with high-risk Human Papillomavirus (HR-HPV) and development of cervical pre-cancer and cancer. Health systems should integrate HPV and HIV services considering particularities of WLHIV when offering comprehensive cervical cancer services. Objectives: To synthesize existing knowledge on cervical cancer epidemiology, as well as access to screening and prevention among women living with HIV in the Americas Region. Methods: Five PICO questions will orient a systematic review of published literature in Medline and LILACS; supplemented with cross-referencing and search of grey literature in Trip and GoogleScholar. The protocol will follow PRISMA-P standards. Two reviewers will screen titles and abstracts independently; disagreements will be solved by consensus. Verification of eligibility based on full-text reading will be carried out. Studies finally included will be assessed for risk of bias based on 
standard tools by type of study. Data extraction tables will be built for every PICO question and reported in a structured format. A meta-analysis will be performed depending upon the results. Discussion: This systematic review anticipates finding valuable information for policy makers and public health actors as it aims to provide new data on a special population from the Americas region.

Keywords

Americas; HIV; uterine cervical neoplasms; cervical intraepithelial neoplasia; mass screening.

\section{RESUMEN}

Contexto: Las mujeres que viven con VIH (WLHIV) tienen mayor riesgo de infección persistente por virus del papiloma humano (VPH) y de desarrollar lesiones precancerosas y cáncer cervicouterino. Los sistemas de salud deben integrar servicios de VIH y VPH que contemplen las particularidades de las WLHIV. Objetivos: Sintetizar la evidencia disponible sobre epidemiología del cáncer cervicouterino y el acceso a servicios de prevención y detección temprana en WLHIV en las Américas. Métodos: Cinco preguntas PICO orientaron una revisión sistemática de literatura publicada en Medline y LILACS, complementada con referencias cruzadas y literatura gris en Trip y Google-Scholar. El protocolo seguirá los estándares de PRISMA-P. Dos investigadores revisarán títulos y resúmenes de manera independiente; los desacuerdos se resolverán por consenso. La elegibilidad se determinará mediante una revisión de texto completo. El riesgo de sesgo se evaluará con instrumentos validados. Se elaborarán tablas de extracción de datos para cada pregunta PICO y se reportarán en formato estructurado. Dependiendo de los resultados, se hará un metanálisis. Discusión: Esta revisión anticipa encontrar información valiosa para decisores y actores de salud pública, ya que proveerá información nueva sobre esta población especial en las Américas.

Palabras clave

VIH; neoplasias del cuello uterino; epidemiología; prevención de enfermedades; tamizaje masivo.

\section{Introduction}

The Americas region accounts for the third highest incidence of cervical cancer among the WHO regions, with more than 70.000 women diagnosed every year $(1,2)$. Cervical cancer represents the first cause of cancer incidence in Bolivia and the second in 16 countries in the Americas. Regarding mortality, cervical cancer is the first cause of cancer mortality in 5 countries and the second cause in 13 countries in the region (1). Within the region, there are evident disparities, with an incidence three times higher in Latin America and the Caribbean than in North America (1).

Currently, 3.5 million people live with HIV in the Americas region, with an estimate of 740.000 women only from Latin America and the Caribbean (3). As mortality is rapidly decreasing due to the higher coverage of antiretroviral (ART) drugs, as well as a stagnant incidence rate, the Region is expected to have an increased number of women living with HIV (WLHIV) in the upcoming years. WLHIV are 4 to 10 times more prone to develop cervical cancer, and synergies among HPV and HIV infection has been elucidated $(2,4,5)$. This represent a significant number of vulnerable women who can be disproportionally impacted by cervical cancer.

Previous systematic reviews and reports have evaluated the burden of cervical cancer and HPV infection amongst WLHIV (6, 7, 8, 9). However, representation of Latin American and Caribbean countries in such reviews has been limited and some recent data from cohort studies suggest significant differences between WLHIV populations from different world regions, not only in cancer incidence but also in associated HPV types and other factors such as exposure to ART $(10,11)$.

Hence, to our knowledge no systematic review on the subject has been carried out for countries in the Americas Region. In this review, the Pan American Health Organization (PAHO) has commissioned the Centro Javeriano de Oncología at the Hospital Universitario San Ignacio in Colombia, to summarize the available data regarding cervical cancer epidemiology, prevention and early detection among WLHIV in Member States of the PAHO (12).

This systematic review is relevant considering the upcoming Global Strategy towards the elimination of cervical cancer as a public health problem, and the regional plans for cervical cancer control and prevention of HIV and sexually transmitted diseases (STDs) $(13,14)$. The review will provide a situation analysis that will elucidate new and valuable information for policy makers for immediate action and will serve as a baseline for the Global Strategy and regional plans. 


\section{Methods}

\section{Aim and objectives}

This systematic review aims to synthesize and report the existing knowledge about cervical cancer epidemiology, as well as access to screening and preventive services for women living with HIV in the Americas region.

This will be achieved by systematically searching, selecting and synthesizing the existing knowledge in order to answer our research questions. Therefore, the specific objectives are:

1. Summarize data on cervical cancer incidence and mortality among WLHIV in the Americas region.

2. Summarize data on prevalence of precancerous lesions among WLHIV in the Americas region.

3. Summarize data on prevalence of HPV infection among WLHIV in the Americas region.

4. Identify and characterize access to screening and preventive services around cervical cancer among WLHIV in the Americas.

Study design

We designed the protocol in accordance with the Preferred Reporting Items for Systematic Reviews and Meta-Analyses Protocols (PRISMA-P) (Figure 1).
Figure 1.

Flowchart of methods according to the PRISMA protocol (15)

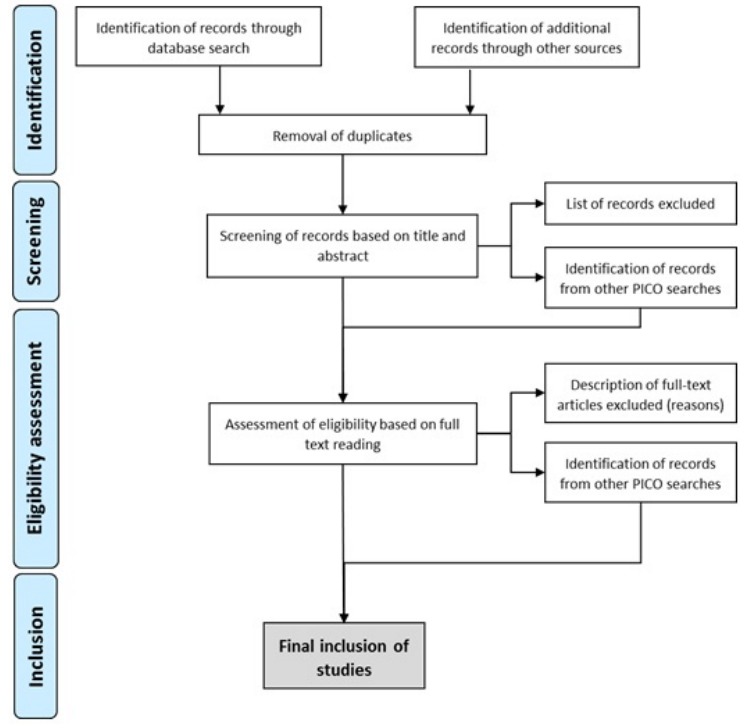

Search strategy

We will systematically search in PubMed via Medline and LILACS databases, and after that, we will conduct updates and searches for grey literature via TRIP-database and Google Scholar. Additionally, cross-referencing will be used to find additional articles for review.

Five PICO questions were defined to carry out a structured search as indicated in Table 1. The terms used for every PICO are presented in the supplementary material (Appendix 1). Accessibility has been defined in three dimensions: physical accessibility, financial affordability, and acceptability (16). These dimensions recall patients and population perspectives beyond the availability and adequacy of health services. For our review, acceptability will be approached in three dimensions: geographic accessibility, economic accessibility, and cultural accessibility. 
Table 1

PICO questions for the systematic search

\begin{tabular}{|c|c|c|c|}
\hline \begin{tabular}{|l|} 
Population \\
\end{tabular} & Intervention & Comparator & Outcomes \\
\hline $\begin{array}{l}\text { Adult women } \\
\text { from the } \\
\text { Americas region }\end{array}$ & HIV infection & $\begin{array}{l}\text { No HIV } \\
\text { infection } \\
\text { (by default) }\end{array}$ & $\begin{array}{l}\text { PICO1: Cervical cancer } \\
\text { incidence/mortality } \\
\text { PICO2: Cervical intraepithelial } \\
\text { neoplasia prevalence } \\
\text { PICO3: HPV prevalence } \\
\text { - High-risk HPV prevalence } \\
\text { - HPV-type prevalence in } \\
\text { precancerous lesions and cervical } \\
\text { cancer } \\
\text { PICO4: Cervical cancer screening } \\
\text { accessibility and acceptability } \\
\text { PICO5: HPV vaccination accessibility } \\
\text { and acceptability }\end{array}$ \\
\hline
\end{tabular}

HIV: Human Immunodeficiency

Virus, HPV: Human Papillomavirus.

We will remove duplicates, and publications will be independently screened based on title and abstract by two members of the research team, and all disagreements will be solved by consensus.

Since a single study could report outcomes for different PICO questions, we will identify and label such studies for their inclusion regarding the corresponding question and outcome. All studies identified through this approach should follow general screening and evaluation procedures as described in the methodology.

\section{Eligibility criteria}

We will select papers based on the following criteria:

1. No language restriction.

2. No publication date range defined.

3. Full text availability.

4. Studies including adult women. Studies only on adolescents or men will be excluded.

5. Studies conducted in populations from PAHO affiliated countries.

6. Outcome specified and data on outcomes available as defined in the PICO questions.

7. For PICOs 1 to 3 , the age as major determinant should be specified (either average age, median age, or age range). Studies with no overall age specified but age groups defined will be included if reporting outcome data at least for one age group.
8. Studies conducted in the general target population (adult women living with HIV). Studies in special populations excluded.

9. Type of study:

1. PICO 1: population based or cohort studies.

2. PICO 2 and 3: cross-sectional or cohort studies.

3. PICO 4,5: descriptive or qualitative studies.

\section{Quality appraisal}

For all included studies, two independent reviewers will assess the methodological quality and risk of bias. For cross-sectional, descriptive and population-based studies, we will use the 20-item appraisal tool for cross-sectional studies (AXIS) (17). Cohort studies will be assessed using the checklist for cohort studies developed by the Scottish Intercollegiate Guidelines Network - SIGN (18). For qualitative studies, we will apply the "Joanna Briggs Institute Critical Appraisal Checklist for critical and interpretive research" (19).

\section{Data management}

Studies retrieved from the search will be listed in Zotero® to identify duplicates. If a given study is published in different journals but with differences in sub-group analyses or presenting updated data, we will extract data from all reports but include in the analysis only the latest data available. If related publications presenting different information are found, they will be included in the analysis indicating that they correspond to a group of reports with the same origin (cluster).

We will prepare three data extraction sheets in Microsoft Excel ${ }^{\circledR}$ for every PICO question: one to register eligibility criteria for all studies selected for full text review, the second for detailed data extraction from studies finally 
included in the review, and the third to register the quality appraisal in detail.

From each study included, we will extract general information (author, title, year of publication, observation period, database source of the study, type of study, and country). We will also extract data on the methods, including sample size, follow-up (cohort studies), eligibility criteria for the study population, age (range, median, mean), and statistics used for significance analysis. Finally, the outcomes for every PICO question will be extracted as absolute numbers when available in addition to the corresponding indicator (incidence rate, prevalence rate, percentage, etc.).

\section{Data analysis}

A separate report for every PICO question will provided. We will present data considering quality of studies and geographic representation (North America and Latin America and the Caribbean), including differences in outcomes and variability in studies.

Depending upon the results, we will also conduct meta-analyses. We will use Revman5 (Cochrane Collaboration, London, United Kingdom) to prepare our review and possible meta-analysis. For this, we will review heterogeneity and quality of studies in addition to availability of detailed information, particularly on age. We will apply a fixed effects model if the heterogeneity is small and a random effects model if the heterogeneity is high. Variation in values by geographic area, mean age and type of study are expected. We will use funnel plots (Christmas tree and "trim and fill") to assess possible publication bias. Since these methods are unreliable if the number of studies is less than 10 , we will only apply it if there are more than 10 studies available.

If no detailed information on age is found, we will contact the corresponding author to retrieve additional data for the analysis. Age group of relevance for the analysis in PICO questions 1 to 3 will be women under 20 years old, women 20 to 29 , women 30 to 49 , and women over 50 years old.

\section{Discussion}

HPV screening and HPV vaccination are the core for cervical cancer elimination globally and regionally (2). Settings with high HIV prevalence have some of the highest cervical cancer incidence rates; thus, the WHO plan highlights the need for greater effort to achieve elimination in such settings.

Previous reviews have included mainly African, European and North American countries $(6,7,8,20,21,22)$ with scarce representation of Latin America and the Caribbean (LAC), which correspond to the region with the second cervical cancer incidence among WHO Regions. To our knowledge, this will be the first review aimed at characterizing epidemiology and preventive activities around cervical cancer among WLHIV in the Americas, and particularly in LAC, a region with high disparities in access to health care.

Our search is designed to ensure the representation and inclusion of all countries in the region. We anticipate finding a large number of papers that might have been disregarded in previous reviews thanks to the use of a Latin American search engine and the inclusion of studies in other languages such as Portuguese and Spanish $(6,7,8)$. We established our clinical questions to provide the most comprehensive evidence of the current situation of cervical cancer disease burden, high-grade precancerous lesions and HR-HPV prevalence in Women Living with HIV in the Americas, as well as the social response to HPV vaccination and cervical cancer screening.

Since we have developed several clinical questions, the final report will be divided into 3 main categories: cervical cancer and highgrade precancerous lesions prevalence (disease), HPV infection, and social response. This will allow a more in-depth statistical and subgroups analysis, per type of study. For outcomes related to the disease and HPV infection, we will assess 
HIV-related factors such as CD4+ cell count and use of antiretroviral therapy amongst studies providing in-depth analysis on the subject, which has not been covered for the Americas region. (6, $7,8)$.

The lack of systematized data on WLHIV and cervical cancer epidemiology and related factors, will difficult the regional efforts towards the control and further elimination of cervical cancer. Our search is targeted to identify all publications on cervical cancer burden and related factors among WLHIV. In this review, the use of a Latin American search engine and the inclusion of studies in other languages, will allow us to identify more papers that may have been disregarded in previous reviews $(6,7,8)$.

\section{Conclusion}

It is paramount to carry out a systematic review and summarize available data on the subject, seeking to set a baseline and provide new and valuable information for policy makers. Our search is targeted to identify all published evidence on cervical cancer burden and HPV infection among WLHIV in the Americas Region.

\section{Acknowledgments}

We thank the comments and guidance by Dr. Juan Sebastián Castillo to structure the PICO questions and the related search strategy.

\section{References}

1. International Agency for Research on Cancer. Global Cancer Observatory: cancer today [Internet]. [Cited 2019 Dec 14]. Available from: h ttps://gco.iarc.fr/

2. World Health Organization. Draft: global strategy towards the elimination of cervical cancer as a public health program [Internet]. 2019 [Cited 2019 Dec 14]. Available from: https://www.who.int/docs/defaul t-source/documents/cervical-cancer-el imination-draft-strategy.pdf?sfvrsn $=3$ 80979d6_4

3. UNAIDS. UNAIDS DATA 2019 [Cited 2019 Dec 14]. Available from: h ttps://www.unaids.org/sites/default/file s/media_asset/2019-UNAIDS-data_en .pdf

4. Abraham AG, D'Souza G, Jing Y, Gange SJ, Sterling TR, Silverberg MJ, et al. Invasive cervical cancer risk among HIVinfected women: a North American Multicohort Collaboration Prospective Study. JAIDS J Acquir Immune Defic Syndr. 2013 Apr;62 (4):405-13.

5. Mohammed D, Shukla P, Babayants Y, Sison R, Slim J. Increased proportions of HIV-infected women met cervical cancer screening guideline in 2016. Int J Womens Health. 2018 Feb;10:83-7.

6. Liu G, Sharma M, Tan N, Barnabas RV. HIV-positive women have higher risk of human papilloma virus infection, precancerous lesions, and cervical cancer: AIDS. 2018 Mar;32(6):795-808.

7. Denslow SA, Rositch AF, Firnhaber C, Ting J, JS Smith. Incidence and progression of cervical lesions in women with HIV: A systematic global review. Int J STD AIDS. 2014 Mar;25(3):163-77.

8. Weldegebreal F, Worku T. Precancerous cervical lesion among HIV-positive women in SubSaharan Africa: a systematic review and meta-analysis. Cancer Control. 2019;26(1):1-11. https://doi.org/10.11 $77 / 1073274819845872$

9. Clifford GM, Goncalves MAG, Franceschi S. Human papillomavirus types among women infected with HIV: 
a meta-analysis. AIDS. 2006;20:233744.

10. Rohner E, Bütikofer L, Schmidlin K, Sengayi M, Maskew M, Giddy J, et al. Cervical cancer risk in women living with HIV across four continents: a multicohort study. Int J Cancer. 2020 Feb 1;146(3):601-609. https://doi.org/1 $0.1002 /$ ijc. 32260

11. Clifford GM, Tully S, Franceschi S. Carcinogenicity of human papillomavirus (HPV) types in HIVpositive women: a meta-analysis from HPV infection to cervical cancer. Clin Infect Dis. 2017 May 1;64(9):1228-35. 12. Pan American Health Orgnization. Member States [Internet]. [Cited 2020 Jan 22]. Available from: https://www.p aho.org/hq/index.php?option $=$ com_c ontent\&view $=$ article $\& i d=103: \mathrm{memb}$ er-states\&Itemid $=1110 \&$ lang $=\mathrm{fr}$

13. Pan American Health Organization. Plan of action for the prevention and control of HIV and sexually transmitted infections 2016-2021. WHO; 2016.

14. Pan American Health Organization. Plan of action for cervical cancer prevention and control 2018-2030 [Internet]. PAHO; 2018 [Cited 2020 Jan 22]. Available from: ht tps://www.paho.org/hq/index.php?opti $\mathrm{on}=\mathrm{com} \_$docman $\&$ view $=$ download \&category_slug =mandates-strategies3448 \&alias $=47584$ - plan-cervical-can cer-2018-2030\&Itemid $=270 \&$ lang $=e$ $\mathrm{n}$

15. Liberati A, Altman DG, Tetzlaff J, Mulrow C, Gotzsche PC, Ioannidis JPA, et al. The PRISMA statement for reporting systematic reviews and meta-analyses of studies that evaluate healthcare interventions: explanation and elaboration. BMJ. 2009 Dec 4;339:b2700. https://doi.org/10.1136/b mj.b2700
16. Evans DB, Hsu J, Boerma $\mathrm{T}$. Universal health coverage and universal access. Bull World Health Organ. 2013 Aug 1;91(8):546-546A. h ttps://doi.org/10.2471/BLT.13.125450

17. Downes MJ, Brennan ML, Williams HC, Dean RS. Development of a critical appraisal tool to assess the quality of cross-sectional studies (AXIS). BMJ Open. 2016 Dec 8;6(12):e011458. https://doi.org/10.11 36/bmjopen-2016-011458

18. Scottish Intercollegiate Guidelines Network. Critical appraisal notes and checklists [Internet]. [Cited 2020 May 28]. Available from: https://www.sign.a c.uk/checklists-and-notes

19. Lockwood C, Munn Z, Porritt K. Qualitative research synthesis: methodological guidance for systematic reviewers utilizing meta-aggregation. Int J Evid Based Healthc. 2015 Sep;13(3):179-87. https://doi.org/10.1 097/XEB.0000000000000062

20. Ofman J, Sullivan S, Neumann P, Chiun-Fang C, Henning J, Wade S, et al. Examining the value and quality of health economic analyses: implications of utilizing the QHES. J Managed Care Pharm. 2003;9(1):53-61.

21. Kelly H, Weiss HA, Benavente Y, de Sanjose S, Mayaud, ART and HPV Revies Group. Association of antiretroviral therapy with highrisk human papillomavirus, cervical intraepithelial neoplasia, and invasive cervical cancer in women living with HIV: a systematic review and metaanalysis. Lancet HIV. 2018t;5(1):e4558. https://doi.org/10.1016/S2352-301 8(17)30149-2

22. Menon S, Rossi R, Zdraveska $\mathrm{N}$, Kariisa M, Acharya SD, Vanden Broeck D, et al. Associations between highly active antiretroviral therapy and the presence of HPV, premalignant and malignant cervical lesions in sub- 
Saharan Africa, a systematic review: current evidence and directions for future research. BMJ Open. 2017;7 (8):e015123. https://doi.org/10. 1136/bmjopen-2016-015123

\section{Abbreviations}

PAHO: Pan American Health Organization

WLHIV: Women Living with HIV

WHO: World Health Organization

CIN: Cervical Intraepithelial Lesions

HPV: Human Papilloma Virus

HR-HPV: High Risk Human Papilloma Virus

\section{Appendix. Search Terms by PICO question}

\section{Appendix 1. \\ PubMed Search Terms}

\section{Population (Questions 1 to 5 )}

(Women) AND ("“Antigua and Barbuda" [Mesh] OR "Argentina" [Mesh] OR "Bahamas" [Mesh] OR "Barbados" [Mesh] OR "Belize" [Mesh] OR "Bolivia" [Mesh] OR "Brazil" [Mesh] OR "Canada" [Mesh] OR "Chile" [Mesh] OR "Costa Rica" [Mesh] OR "Cuba" [Mesh] OR "Dominica" [Mesh] OR "Dominican Republic" [Mesh] OR "Ecuador" [Mesh] OR "El Salvador" [Mesh] OR "Grenada" [Mesh] OR "Guatemala" [Mesh] OR "Guyana" [Mesh] OR "Haiti" [Mesh] OR "Honduras" [Mesh] OR "Jamaica" [Mesh] OR "Mexico" [Mesh] OR "Nicaragua" [Mesh] OR "Panama" [Mesh] OR "Paraguay" [Mesh] OR "Peru" [Mesh] OR "Saint Lucia" [Mesh] OR "Saint Vincent and the Grenadines" [Mesh] OR "Saint Kitts and Nevis" [Mesh] OR "Suriname" [Mesh] OR "Trinidad and Tobago" [Mesh] OR "United States" [Mesh] OR "Uruguay" [Mesh] OR "Venezuela" [Mesh] OR "Latin America" [Mesh] OR "South America" [Mesh] OR "North America" [Mesh] OR "Central America" [Mesh] OR "Caribbean Region" [Mesh] OR "West Indies" [Mesh] OR America OR America's region OR Americas

Intervention (

"HIV Infections" [Mesh] OR "HIV Seroprevalence" [Mesh] OR "HIV Seropositivity" [Mesh] OR "HIV" [Mesh]

Outcomes

Question

"Uterine Cervical Neoplasms" [Mesh] OR cervical OR cervix OR tumor* OR neoplasm* OR cancer OR uterine AND Incidence OR "Cohort Studies" [Mesh] OR new AND cases OR risk OR incidence [MeSH: noexp] OR ("Mortality" [Mesh] OR "mortality" [Subheading]) OR "Death" [Mesh] OR mortality OR death

Question 2

"Cervical Intraepithelial Neoplasia" [Mesh] OR "Adenocarcinoma in situ" [Mesh] OR CIN AND Incidence OR "Cohort Studies" [Mesh] OR new AND cases OR risk OR "Prevalence" [Mesh] OR "Cross-Sectional Studies" [Mesh] OR prevalonce OR "Incidence" [Mesh]

Question 3

("Papillomavirus Infections" [Mesh] OR HPV infection OR "Human papillomavirus 16" [Mesh] OR "Human papillomavirus 18" [Mesh] OR "Human papillomavirus 31" [Mesh] OR Human papillomavirus type $16,18,11,6,31,33,45,52,58$ OR HPV type $16,18,11,6,31,33,45,52,58)$ AND ("Prevalence" [Mesh] OR "Cross-Sectional Studies" [Mesh] OR prevalence)

Question 4

"Health Services Accessibility" [Mesh] OR accessibility OR geographic access OR cultural access $O R$ economic access OR " "Patient Acceptance of Health Care" [Mesh] OR acceptance OR acceptability) AND "Early Detection of Cancer" [Mesh] OR "Mass Screening" [Mesh]) AND "Uterine Cervical Neoplasms" [Mesh "Cerical Intrepithelial Neoplasia" [Mes] OR "Aleno Cervical Neoplasms" (Meshl "Cervical Intraepithelial -Neoplasions Question 5

("Health Services Accessibility" [Mesh] OR accessibility OR access geographical OR cultural OR economic) OR ("Patient Acceptance of Health Care" [Mesh] OR acceptance OR acceptability) AND ("Papillomavirus Vaccines" [Mesh] OR "Human Papillomavirus Recombinant Vaccine Quadrivalent, Types 6, 11, 16, 18" [Mesh] OR "Vaccination" [Mesh] OR HPV OR vaccination OR bivalent $A N D$ vaccine $O R$ nonavalent $A N D$ vaccine)
Apendix B. LILACS Search Terms

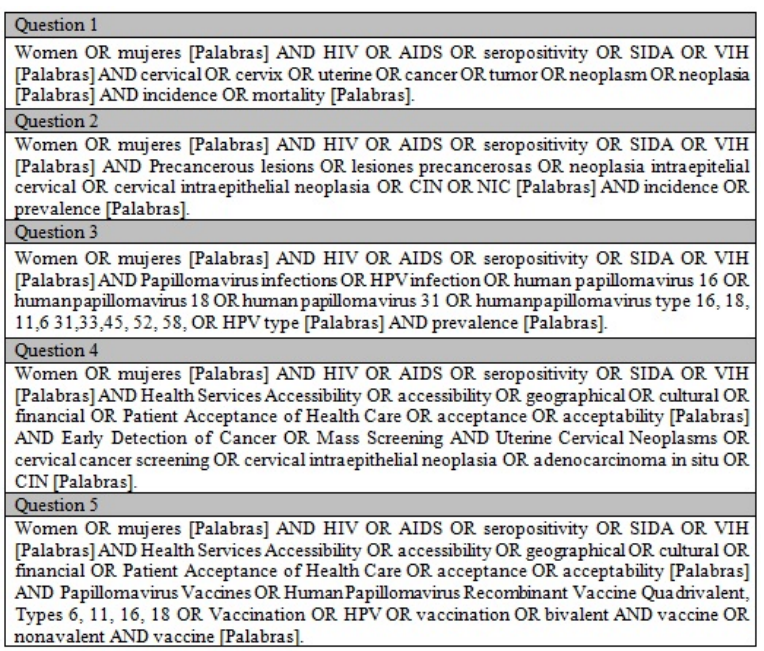

Notes

Conflict of interests No competing interests are declared by the authors.

Funding This study will be funded by the Pan American Health Organization under the contract CON19-00016533 with the Hospital Universitario San Ignacio. Ethical considerations This study will not include human or animal participants; therefore, it does not require ethical approval. Author's contribution RM and MdM conceptualized the study and prepared the draft proposal. RM, MdM, BN and $\mathrm{MC}$ contributed to the development of the background and planned the output of the research as well of the design of the study with $\mathrm{CO}$ and GF. CO, GF and MC prepared the manuscript, and RM, MdM and BN critically reviewed it. All authors (RM, MdM, $\mathrm{BN}, \mathrm{MC}, \mathrm{CO}$ and $\mathrm{GF}$ ) contributed to the reviewed draft version of the manuscript and approved the final version. 